\title{
AÇÃO DE BIOESTIMULANTES EM CULTIVARES COMERCIAIS DE SOJA NA REGIÃO NORTE DO VALE ARAGUAIA - MT
}

\author{
USE OF DIFFERENT BIOESTIMULANTS AMONG DIFFERENT COMMERCIAL SOY \\ CULTIVARS IN THE NORTH REGION OF VALE ARAGUAIA - MT
}

\author{
Lauro Luiz Mota Araújo ${ }^{1}$ (D), Denis Tomas Ramos ${ }^{2}$ (D), Elizeu Luiz Brachtvogel ${ }^{3}$ (D) , \\ Anderson Roberto Kovalski ${ }^{4}$ (D)
}

Recebido em 27 de abril de 2021 | Aprovado em 21 de junho de 2021

\begin{abstract}
RESUMO
Os bioestimulantes influenciam diretamente no desenvolvimento vegetal, podendo desempenhar papel importante no incremento de produtividade da cultura da soja. Desta maneira o objetivo deste trabalho foi avaliar o desenvolvimento e a produtividade de seis cultivares de soja (Glycine max L.) (HO CRISTALINO, M 8644 IPRO, TMG 2185 IPRO, NS 7901 IPRO, M 7739 IPRO e CZ48B32 IPRO) em função da pulverização de três bioestimulantes (Proggib®, Stimulate ${ }^{\circledR}$, biozyme ${ }^{\circledR}$ ) e uma testemunha, totalizando 24 tratamentos. O trabalho foi realizado em Confresa, nordeste de Mato Grosso, em delineamento experimental inteiramente casualizado (DIC). Foram realizadas duas pulverizações com intervalo de 10 dias, iniciando-se quando as plantas se encontravam no estádio fenológico R1, e a segunda R1 + 10, utilizando das dosagens de $250 \mathrm{ml}^{\text {. ha- }}$ ${ }^{1}$ (Stimulate®), $5 \mathrm{~g} \mathrm{há}^{-1}$ (Progibb®) e $200 \mathrm{ml} \mathrm{ha}^{-1}$ (Biozyme®). Quando as plantas de soja estavam nos estádios fenológicos R6, R7 e R8 foram avaliadas as características de altura de planta, número de nós por planta, número de ramos reprodutivos por planta, número total de vagens por planta, número de grãos por planta, massa de mil grãos e produtividade final. $\mathrm{O}$ fator de variação cultivar foi significativo para todas as variáveis analisadas. $\mathrm{O}$ fator bioestimulante foi significativo para a variável altura de planta, massa de mil grãos e produtividade e houve interação significativa entre cultivar e bioestimulantes para as características altura de plantas, total de vagens por plantas, massa de mil grãos e produtividade. Em relação a diferença entre os tratamentos com bioestimulantes e testemunha só houve diferença significativa nas cultivares M 8644 IPRO e TMG 2185 IPRO.
\end{abstract}

Palavras-chave: Produtividade da soja; Bioestimulantes; Cultivares.

\footnotetext{
${ }^{1}$ Graduando em Agronomia pelo Instituto Federal de Educação, Ciência e Tecnologia de Mato Grosso (IFMTCampus Confresa). Confresa, MT, Brasil. Endereço para correspondência: Av. Vilmar Fernandes, 300, Setor Santa Luzia, Confresa, MT, Brasil, CEP: 78652-000. E-mail: lauroluizmota@gmail.com

${ }^{2}$ Doutor em Agricultura Tropical pela Universidade Federal de Mato Grosso. Pesquisador e Consultor Técnico na Empresa Xingu Pesquisa e Consultoria Agronômica. Endereço para correspondência: BR ${ }^{-158}$, Confresa, MT, Brasil, CEP: 78652-000. E-mail: denis.t.ramos@gmail.com.

${ }^{3}$ Doutor em Agricultura Tropical pela Universidade Federal de Mato Grosso. Pesquisador e Consultor Técnico na Empresa Xingu Pesquisa e Consultoria Agronômica. Endereço para correspondência: BR ${ }^{-1} 58$, Confresa, MT, Brasil, CEP: 78652-000. E-mail: denis.t.ramos@gmail.com.

${ }^{4}$ Graduando em Agronomia pelo Instituto Federal de Educação, Ciência e Tecnologia de Mato Grosso (IFMTCampus Confresa). Confresa, MT, Brasil. Endereço para correspondência: Av. Vilmar Fernandes, 300, Setor Santa Luzia, Confresa, MT, Brasil, CEP: 78652-000. E-mail: andersonrk.agro@gmail.com
} 


\begin{abstract}
Biostimulants directly influence plant development and can play an important role in increasing the productivity of soybean crops. Thus, the objective of this work was to evaluate the development and productivity of six soybean cultivars (Glycine max L.) (HO CRISTALINO, M 8644 IPRO, TMG 2185 IPRO, NS 7901 IPRO, M 7739 IPRO and CZ48B32 IPRO) according to spraying of three biostimulants (Proggib®, Stimulate®, biozyme $($ ) and a control, totaling 24 treatments. The work was carried out in Confresa, northeast of Mato Grosso, in a completely randomized design (DIC). Two sprays were performed with an interval of 10 days, starting when the plants were in the phenological stage R1, and the second R1 + 10, using dosages of $250 \mathrm{ml}$. $\mathrm{ha}^{-1}$ (Stimulate $\left.\AA\right), 5 \mathrm{~g} \mathrm{ha}^{-1}$ (Progibb $\left.\AA\right)$ and $200 \mathrm{ml} \mathrm{ha}^{-1}$ (Biozyme $\left.\AA\right)$. When the soybean plants were in the phenological stages R6, R7 and R8 the characteristics of plant height, number of nodes per plant, number of reproductive branches per plant, total number of pods per plant, number of grains per plant, mass were evaluated thousand grains and final productivity. The cultivar variation factor was significant for all variables analyzed. The biostimulating factor was significant for the variable plant height, mass of a thousand grains and productivity and there was a significant interaction between cultivar and biostimulants for the characteristics of plant height, total pods per plant, mass of a thousand grains and productivity. Regarding the difference between treatments with biostimulants and control, there was only a significant difference in cultivars M 8644 IPRO and TMG 2185 IPRO.
\end{abstract}

Keywords: Soy productivity; Biostimulants; Cultivars.

\title{
1 Introdução
}

A soja é a principal commodity agrícola brasileira, com grande importância em termos de produção de grãos e exportação (KLAHOLD et al, 2006). Na safra 2018/19 o Brasil semeou cerca de 35,8 milhões de hectares da oleaginosa, e o estado de Mato Grosso se destaca como maior produtor de soja, com cerca de $26,7 \%$ da área e $28,9 \%$ da produção total de soja do Brasil (CONAB, 2019).

Dessa forma, torna-se a busca por maiores produtividades da soja algo constante e desafiador ao produtor rural ao longo do tempo. Segundo a Companhia Nacional de Abastecimento (CONAB) a ascendência na produção brasileira de soja ao longo dos últimos 20 anos não está interligada a elevação na capacidade produtiva em áreas já cultivadas, mas sim pelo aumento do número de áreas cultivadas, mediante expansão de novas fronteiras agrícolas e, a abertura de novas áreas nas próprias unidades agrícolas.

Em meio esse encalço, no Brasil para algumas culturas os avanços tecnológicos já proporcionaram níveis satisfatórios de produtividade, indicando não mais restrições de ordem nutricional e/ou hídrica, passando-se a buscar novas alternativas de manejo que possam contribuir ao aumento da produção, o que tem levado ao uso de bioestimulantes como opção (BERTOLIN et. al., 2010).

Os bioestimulantes são classificados como uma mistura de dois ou mais reguladores vegetais com a presença de altos níveis de nutrientes (SOUZA, 2003). Durante o desenvolvimento das plantas, podem favorecer o crescimento vegetal através de uma maior 
diferenciação, elongação e divisão celular, resultando no aumento da capacidade de absorção de água e nutrientes, interferindo positivamente no desenvolvimento (germinação de sementes, crescimento e desenvolvimento, floração, frutificação, senescência) e por fim na produtividade das mesmas (SILVA et al., 2008).

Ao encontro deste objetivo se faz necessário a implantação de novos estudos que visem obtenção novas tecnologias que possam refletir significativa melhoria do sistema produtivo, acarretando ganhos na produção final e principalmente o aumento da rentabilidade do sistema de cultivo da soja. Em que, hipóteses são lançadas se as aplicações em pequenas concentrações de hormônios vegetais podem influenciar a planta de soja a produzir uma maior quantidade de ramos laterais, induzindo maior pegamento floral, o aumento na formação de vagens e altura de plantas e, a maior quantidade de grãos por planta.

Para se comprovar de forma técnica e cientifica os efeitos dos bioestimulantes no desenvolvimento das plantas de soja, este trabalho teve como principal objetivo avaliar a utilização de diferentes bioestimulantes entre diferentes cultivares comerciais de soja na região norte do Vale Araguaia - MT.

\section{Metodologia}

O experimento foi instalado no campo experimental da Xingu Pesquisa e Consultoria Agronômica Ltda-me, situada na margem da BR 158 KM 152 sob coordenadas S10 43' 48,2" e W051'35'42,3”, município de Confresa, região nordeste do Estado de Mato Grosso. A região apresenta altitude média de 230 metros, e segundo a classificação de Köppen enquadra-se no clima tropical úmido (Aw), verão chuvoso e inverno seco. A temperatura média durante execução do trabalho foi de $26,1^{\circ} \mathrm{C}$ e precipitação total de $1.469,30 \mathrm{~mm}$.

O Solo da área experimental conforme Embrapa (2013) foi classificado como um Latossolo Amarelo (LV) de textura média sob relevo plano. Os dados das características químicas encontram-se na tabela 1.

Tabela 1 - Resultado da análise química do solo.

\begin{tabular}{|c|c|c|c|c|c|c|c|}
\hline \multirow{2}{*}{$\begin{array}{l}\text { Prof. } \\
(\mathrm{cm})\end{array}$} & \multicolumn{2}{|c|}{ pH } & Pmeh $^{-1}$ & P rem. & P res. & $\mathrm{Na}^{+}$ & $\mathbf{K}^{+}$ \\
\hline & $\mathrm{H}_{2} \mathrm{O}$ & $\mathrm{CaCl}_{2}$ & \multicolumn{3}{|c|}{----------mg dm ${ }^{-3}$} & \multicolumn{2}{|c|}{ - } \\
\hline $0-10$ & 6,2 & 5,6 & 65,4 & 34,6 & 146,7 & 32,30 & 84,80 \\
\hline \multirow[b]{2}{*}{ Prof. $(\mathrm{cm})$} & $\mathbf{S}$ & $\mathbf{K}^{+}$ & $\mathrm{Ca}^{2+}$ & $\mathrm{Mg}^{2+}$ & $\mathrm{Al}^{3+}$ & $\mathbf{H}+\mathbf{A l}$ & M.O. \\
\hline & \multicolumn{6}{|c|}{ - } & -----Dag kg-1----. \\
\hline $0-10$ & 5 & 0,22 & 3,05 & 0,57 & 0,00 & 3,20 & 3,12 \\
\hline
\end{tabular}




\begin{tabular}{|c|c|c|c|c|c|c|c|c|c|}
\hline \multirow{2}{*}{$\begin{array}{l}\text { Prof. } \\
(\mathrm{cm})\end{array}$} & B & $\mathbf{C u}$ & $\mathbf{F e}$ & Mn & $\mathbf{Z n}$ & SB & $\mathbf{T}$ & $\mathbf{T}$ & \multirow{2}{*}{$\frac{\mathbf{V}}{------(\%) \text {----- }}$} \\
\hline & \multicolumn{3}{|c|}{--------mg dm'------- } & \multicolumn{5}{|c|}{ 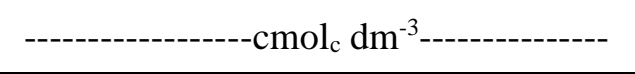 } & \\
\hline $0-10$ & 0,15 & 0,3 & 71 & 16 & 0,4 & 3,8 & 7,0 & 3,80 & 54,90 \\
\hline \multirow{2}{*}{\multicolumn{2}{|c|}{ Prof. (cm) }} & $\mathrm{Ca} / \mathrm{Mg}$ & $\mathrm{Ca} / \mathrm{K}$ & & $\mathrm{Mg} / \mathrm{K}$ & $\mathrm{Ca} / \mathrm{CTC}$ & & /CTC & K/CTC \\
\hline & & & & \multicolumn{2}{|c|}{ Relações } & \multicolumn{3}{|c|}{$(\%)$} & \\
\hline $0-10$ & & 5,3 & 13,9 & & 2,6 & 44 & & 8 & 3 \\
\hline
\end{tabular}

Extrator: $\mathrm{P}, \mathrm{K}, \mathrm{Cu}, \mathrm{Fe}, \mathrm{Mn}, \mathrm{Zn}, \mathrm{Na}=($ Mehlich$) ; \mathrm{Al}, \mathrm{Ca}, \mathrm{Mg}=(\mathrm{KCl}$ 1M); P-Resina = (Resina Trocadora de Íons); M.O. $=(\mathrm{Na} 2 \mathrm{Cr} 2 \mathrm{O} 7.2 \mathrm{H} 2 \mathrm{O}+\mathrm{H} 2 \mathrm{SO} 4 ; \mathrm{S}=(\mathrm{Ca}(\mathrm{H} 2 \mathrm{PO} 4120,01 \mathrm{M}$.

O projeto foi conduzido em arranjo fatorial 6 cultivares (HO cristalino, M 8644 IPRO, TMG 2185 IPRO, NS 7901 RR, M 7739 IPRO e CZ48B32 IPRO) x 3 Bioestimulantes, sendo eles Stimulate ${ }^{\circledR}(0,09$ g.L cinetina + 0,05 g.L Ácido indol butirico + 0,05 g.L Ácido giberélico + 4\% de molibdênio) Progibb® (Ácido giberélico 400 g/kg) e Biozyme® (2,43\% de Zn, 1,73\% de $\mathrm{N}, 5 \% \mathrm{~K}_{2} \mathrm{O}, 0,08 \% \mathrm{~B}, 0,49 \%$ de Fe, $1 \%$ de $\mathrm{Mn}$, e $2,1 \%$ de $\mathrm{S}$ ) e uma testemunha sem aplicação, sob delineamento inteiramente casualizado (DIC), totalizando 24 tratamentos em quatro repetições. Cada parcela experimental foi constituída por 12 linhas de semeadura espaçadas a $0,45 \mathrm{~m}$, com $3 \mathrm{~m}$ de comprimento. Na tabela 2 estão descritas as características agronômicas das cultivares utilizadas no experimento.

Tabela 2. Características agronômicas das cultivares utilizadas no experimento.

\begin{tabular}{cccccc}
\hline Cultivar & $\begin{array}{c}\text { Hábito de } \\
\text { crescimento }\end{array}$ & $\begin{array}{c}\text { Grau de } \\
\text { maturidade }\end{array}$ & $\begin{array}{c}\text { Ciclo médio } \\
\text { (dias) }\end{array}$ & $\begin{array}{c}\text { População } \\
\text { mil plan./ha }\end{array}$ & $\begin{array}{c}\text { Exigência de } \\
\text { fertilidade }\end{array}$ \\
\hline HO CRISTALINO & Indeterminado & 8.3 & 115 & 280 & Alta \\
M 8644IPRO & Determinado & 8.6 & 120 & 220 & Média \\
TMG 2185IPRO & Determinado & 8.5 & 117 & 244 & Média \\
NS 7901RR & Indeterminado & 7.9 & 110 & 260 & Alta \\
M 7739IPRO & Semi-determinado & 7.7 & 102 & 260 & Alta \\
CZ48B32IPRO & Determinado & 8.3 & 113 & 240 & Alta \\
\hline
\end{tabular}

Previamente a implantação do experimento, no dia 25 de outubro de 2018, o solo foi submetido a adubação de cobertura com $160 \mathrm{~kg} \mathrm{ha}^{-1}$ de cloreto de potássio, e na semeadura, realizada em 5 de novembro de 2018, utilizou-se de adubação de base com $350 \mathrm{~kg}^{\text {ha- }}{ }^{1}$ de MAP, seguindo-se a adubação preconizada no Boletim de Pesquisa 2017/2018 da Fundação Mato Grosso, referência para a cultura no Estado de Mato Grosso (Fundação..., 2017). As sementes 
foram tratadas com o fungicida Maxim advanced (Tiabendazol, Metalaxil, Fludioxonil) na dose de $100 \mathrm{ml}$ p.c/ $100 \mathrm{~kg}$ de sementes e com o inseticida Fortenza 600 FS (Ciantraniliprole) na dose de $200 \mathrm{ml}$ p.c/ $100 \mathrm{~kg}$ sementes, posteriormente foram inoculadas com bactérias do gênero Bradyrhizobium, específicas para cultura da soja.

Foram realizadas duas pulverizações com intervalo de 10 dias, iniciando-se quando as plantas se encontravam no estádio fenológico R1 e a segunda R1+10, utilizando-se das dosagens de $250 \mathrm{ml} \mathrm{ha}^{-1}$ (Stimulate $\AA$ ), $5 \mathrm{~g} \mathrm{ha}^{-1}$ (Progibb®) e $200 \mathrm{ml} \mathrm{ha}^{-1}$ (Biozyme®).

As pulverizações dos bioestimulantes foram efetuadas com a utilização de equipamento costal ( $\mathrm{CO}_{2}$ Pressurizado), a um volume de calda de $150 \mathrm{~L} / \mathrm{ha}$, utilizando-se de bicos tipo Leque J3D - 100015 em condições atmosféricas adequadas. Todos os tratos culturais necessários referentes ao controle de plantas daninhas, doenças e insetos pragas, ocorreram dentro do modelo padrão de manejo determinado pela estação experimental com base em levantamentos semanais, seguindo as recomendações de uso de cada produto aprovado pelo Ministério da Agricultura (MAPA) para a cultura (Anexo IV).

Foram realizadas as seguintes avaliações:

\section{(i) Número de vagens e grãos por planta:}

- Número de vagens: Foram coletadas três plantas por parcela experimental no estágio fenológico R6, determinado o número de vagens com 1, 2, 3 e 4 grãos e chochas.

- Número de grãos: Após ser feita a contagem das vagens, se multiplicou pelo número respectivo de grãos de cada vagem.

\section{(ii) Número de nós e ramos reprodutivos por planta:}

- Número nós: Foram coletadas três plantas por parcela experimental no estágio fenológico R6, determinado o número nós de cada planta.

- Número de ramos reprodutivos: Foram coletadas três plantas por parcela experimental no estágio fenológico R6, determinado o número ramos reprodutivos (que continham vagem) de cada planta.

\section{(iii) Rendimento:}

- Massa de mil grãos (g) e produção (sc ha-1): A massa de mil grãos, foi avaliada a partir de quatro repetições de cem grãos, o resultado multiplicado por 10, o resultado foi expresso em gramas e corrigidos para $13 \%$ de umidade, mensurados em balança de precisão $0,01 \mathrm{~g}$. A colheita foi efetuada 5 dias após a dessecação. A determinação da produção foi realizada com a coleta de plantas em dois metros lineares por parcela experimental, em que, as plantas dos respectivos tratamentos foram submetidas a trilhagem com posterior determinação do 
percentual de umidade dos grãos a partir de três médias do medidor Motomco 999 CP. O cálculo do peso de mil grãos e rendimento por hectare por tratamento tomou-se como base a padronização à $13 \%$ de base úmida.

Os dados foram submetidos a testes de normalidade de distribuições e homogeneidade de variância, conforme técnica de Yeo; Johnson (2000) para aderência, com posterior padronização, com o objetivo de enquadrar os valores em uma escala de valores positivos única, variando entre 0 e 1, conforme Glover et al. (2000). Posterior a sua adequação os resultados foram submetidos à análise de variância e as médias comparadas pelo teste de Scott-Knott ( $\mathrm{p}<$ 0,5), utilizando-se o pacote computacional SISVAR, versão 4.0 (FERREIRA, 2000).

\section{Resultados e Discussão}

O fator de variação cultivar foi significativo para todas as variáveis analisadas. O fator bioestimulante foi significativo para a variável altura de planta, massa de mil grãos e produtividade e houve interação significativa entre cultivar e bioestimulantes para as características altura de plantas, total de vagens por plantas, total de grãos por planta, massa de mil grãos e produtividade, já para os fatores de variação número de ramos reprodutivos e número de nós por planta não houve interação entre cultivar e bioestimulantes. Tais resultados estão descritos na Tabela 2.

Tabela 3 - Resumo do quadro de análise de variância da altura de plantas (AP), número de ramos reprodutivos (NRR), número de nós por planta (NNP), total de vagens por planta (TVP), total de grãos por planta (TGP), peso de mil grãos (PMG) e produtividade (PROD) da soja em função do manejo de variedades e bioestimulantes em Confresa-MT. IFMT. 2020.

\begin{tabular}{|c|c|c|c|c|c|c|c|c|}
\hline \multirow{2}{*}{\multicolumn{2}{|c|}{ FV GL }} & & \multicolumn{6}{|c|}{ QUADRADOS MÉDIOS } \\
\hline & & $\mathrm{AP}$ & NRR & NNP & TVP & TGP & PMG & PROD \\
\hline Cult. & 5 & $2362,3 * *$ & $15,4 * *$ & $65,4^{* *}$ & $1796,5 * *$ & $4305,1 * *$ & $913,7 * *$ & $1240,5 * *$ \\
\hline Bioes. & 3 & $418,8 * *$ & $2,3 \mathrm{~ns}$ & $5,0 \mathrm{~ns}$ & $301,2 \mathrm{~ns}$ & $2131,9 \mathrm{~ns}$ & $218,7 * *$ & $387,2 * *$ \\
\hline Cult.*bio & 15 & $110,2 * *$ & $5,4 \mathrm{~ns}$ & $4,8 \mathrm{~ns}$ & $584,7 * *$ & $3118,6^{* *}$ & $16,0 * *$ & $100,2 * *$ \\
\hline $\mathrm{CV}(\%)$ & & 8,7 & 29,1 & 18,7 & 16,4 & 16,1 & 1,45 & 7,2 \\
\hline Méd Ger & & 82,8 & 7,2 & 14,8 & 92,7 & 212,0 & 68,3 & 82,6 \\
\hline
\end{tabular}

** significativo ao nível de $5 \%$ pelo Teste " $F$ " ( $p<0,05)$, (ns) não significativo (p>=0,05).

Na tabela 2 pode-se observar que o coeficiente de variação (CV) entre as características estudadas se manteve sempre abaixo de 20 para as características AP, NNP, TVP, TGP, PMG E PROD, isso demonstra que o experimento teve uma boa precisão experimental para essas 
características, já para o fator de variação NRR o coeficiente ficou próximo de 30, indicando baixa precisão experimental (PIMENTEL GOMES, 2000).

Na tabela 3 estão descritas as médias para as variáveis altura de planta, número de nós por planta, número de ramos reprodutivos, total de vagens por planta, total de grãos por planta, peso de mil grãos e produtividade. Em todas as características avaliadas o fator de variação cultivar foi significativo. Tal resultado já era esperado tendo em vista que cada cultivar tem sua linhagem genética, conjunto de genes diferente uma das outras.

Na Figura 1 estão apresentados os resultados das médias de altura de plantas resultantes da interação entre cultivares e bioestimulantes. Dentre as cultivares estudadas a que teve o maior crescimento foi a cultivar HO CRISTALINO no tratamento com Progibb® com média de $114 \mathrm{~cm}$, diferenciando significativamente para os manejos onde foi aplicado o Stimulate ${ }$, Biozyme ${ }^{\circledR}$ e a testemunha, com reduções de $19 \mathrm{~cm}, 25,34 \mathrm{~cm}, 15,34 \mathrm{~cm}$, respectivamente.

Tabela 4 - Diferença entre cultivares para as variáveis: Altura de planta (AP), número de nós por planta (NNP), número de ramos reprodutivos (NRR), total de vagens por planta (TVP), total de grãos por planta (TGP), peso de mil grãos (PMG) e produtividade (PROD) na cultura da soja em Confresa-MT. IFMT. 2018/2019.

\begin{tabular}{lccccccc}
\hline CULTIVAR & AP & NRR & NNP & TVP & TGP & PMG & PROD \\
\hline M 8644 IPRO & $77,83 \mathrm{~B}$ & $13,33 \mathrm{~B}$ & $7,00 \mathrm{~B}$ & $99,33 \mathrm{~A}$ & $207,41 \mathrm{~B}$ & $169,26 \mathrm{C}$ & $80,65 \mathrm{C}$ \\
NS 7901 IPRO & $99,66 \mathrm{~A}$ & $17,75 \mathrm{~A}$ & $6,25 \mathrm{~B}$ & $83,08 \mathrm{~A}$ & $160,91 \mathrm{D}$ & $173,88 \mathrm{~B}$ & $63,60 \mathrm{D}$ \\
M 7739 IPRO & $64,75 \mathrm{D}$ & $12,58 \mathrm{~B}$ & $8,41^{\mathrm{a}}$ & $88.08 \mathrm{~A}$ & $202,08 \mathrm{~B}$ & $194,28 \mathrm{~A}$ & $83,60 \mathrm{C}$ \\
CZ 48B32 IPRO & $73,66 \mathrm{C}$ & $13,66 \mathrm{~B}$ & $8,33^{\mathrm{a}}$ & $75,75 \mathrm{~B}$ & $186,41 \mathrm{C}$ & $167,42 \mathrm{C}$ & $87,37 \mathrm{~B}$ \\
HO CRISTALINO & $99,08 \mathrm{~A}$ & $17,75 \mathrm{~A}$ & $5,58 \mathrm{~B}$ & $83,41 \mathrm{~B}$ & $210,33 \mathrm{~B}$ & $152,71 \mathrm{D}$ & $92,81 \mathrm{~A}$ \\
TMG 2185 IPRO & $81,91 \mathrm{~B}$ & $13,58 \mathrm{~B}$ & $7,50^{\mathrm{a}}$ & $101,25 \mathrm{~A}$ & $241,58 \mathrm{~A}$ & $152,08 \mathrm{D}$ & $87,49 \mathrm{~B}$ \\
\hline
\end{tabular}

Médias seguidas de mesma letra na coluna não diferem entre si pelo teste de Scott-Knott $(\mathrm{p} \leq 0,05)$. 
Figura 1 - Desdobramento da interação entre cultivares x bioestimulantes para a variável altura de plantas (cm) na cultura da soja em Confresa-MT. IFMT. 2020.

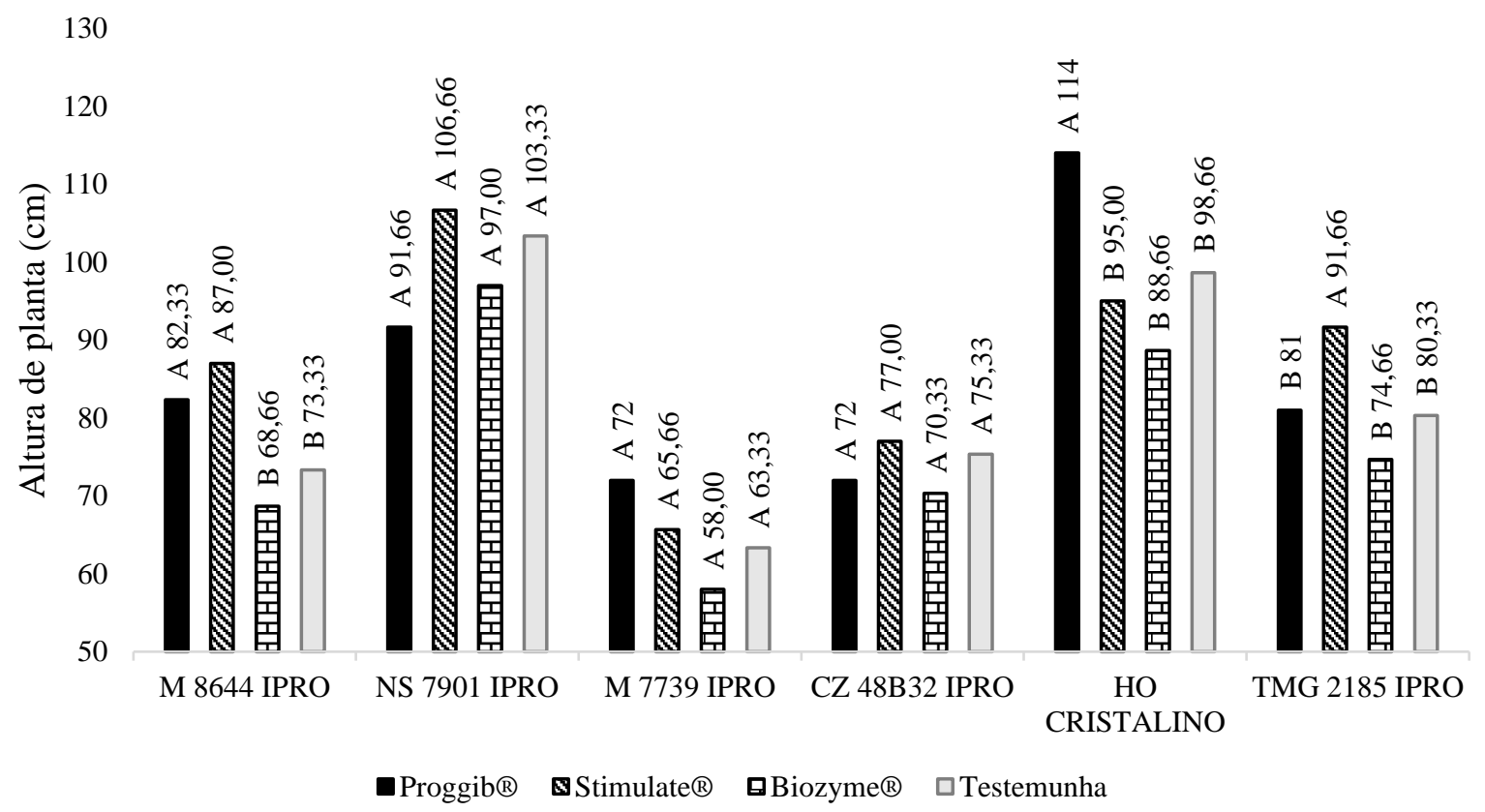

Médias seguidas de mesma letra maiúscula não diferem entre si pelo teste de Scott-Knott $(\mathrm{p} \leq 0,05)$.

A cultivar TMG 2185 IPRO, quando submetida a aplicação de Stimulate ${ }^{\circledR}$ expressou uma altura de $91,66 \mathrm{~cm}$, diferindo estatisticamente dos demais tratamentos. Já as cultivares NS 7901 IPRO, M 7739 IPRO, CZ 48B32 IPRO, não diferiram significativamente em nenhum dos manejos adotados, isso demonstra que embora sejam da mesma espécie as cultivares podem expressar resposta diferentes umas das outra. Estes resultados confirmam as afirmações de Taiz; Zeiger (2004), quando afirmam que o crescimento das plantas é promovido pela ação da giberilina, onde está aumenta a divisão e o alongamento celular.

Segundo o que descreve Garcia et al. (2009) a variável mais relevante na qual se diferencia as cultivares da soja é no crescimento, assim como Hermes; Nunes; Nunes (2015), verificaram que os bioestimulantes influenciam no desenvolvimento da cultura, possivelmente estimulada pelo maior crescimento dos entrenós, pois a giberilina estimula a expansão celular.

Resultado diferente ao deste trabalho fora encontrado por Klahold et al. (2006) onde relataram que não encontraram diferenças relevantes na altura das plantas em resposta ao uso de bioestimulantes com a cultura da soja, pois as plantas apresentaram uma redução no índice de área foliar. 
O número de vagens contendo um, dois, três e quatro grãos, de forma geral sofreram uma alta interferência ao uso de bioestimulantes (Tabela 5).

Com relação ao número total de vagens (Figura 2) a maior média encontrada foi a da cultivar NS 7901 IPRO quando submetida a aplicação de Stimulate®, a média do tratamento foi de 122,33 vagem, no entanto o tratamento não diferenciou estatisticamente dos tratamentos com Biozyme ${ }^{\circledR}$ e testemunha, mesmo tendo uma diferença de 5,33 vagens e 11,67 vagens respectivamente.

Outra cultivar que expressou diferença significativa entre os tratamentos foi a M 7739 IPRO, onde a maior média encontrada foi de 103,66 vagens e a menor foi de 64 vagens, uma diferença de 39,66 vagens. As cultivares M 8644 IPRO, CZ 48B32 IPRO, HO CRISTALINO e TMG 2185 IPRO, não apresentaram diferença significativa entre os tratamentos adotados mesmo com diferenças de até 23,67 vagens de um tratamento para outro.

Segundo Carvalho et al (2013) a aplicação de bioestimulantes vegetais, impulsionou a planta a se desenvolver melhor, em alongamento, em comprimento e aumento do diâmetro de caule, proporcionando com isso um maior engalhamento e consequentemente um maior número de vagens.

Da mesma forma, o número de vagens por planta e peso de mil grãos, obteve acréscimo, resultando assim no aumento de produtividade. Albrecht et al. (2011) estudaram os efeitos do bioestimulante no desenvolvimento das plantas e nas características que influenciam na produção de grãos da soja, no qual verificaram que o uso do biorregulador aumentaram a produção da cultura, gerando um maior número de vagens e uma maior produtividade. 
Tabela 5 - Valores das médias para as variáveis vagens com um, dois, três e quatro grãos, em Confresa-MT, 2018/2019.

\begin{tabular}{|c|c|c|c|c|c|}
\hline Bioestimulante & Cultivar & $\begin{array}{l}n^{\circ} \text { Vagens } \\
\text { um grão }\end{array}$ & $\begin{array}{l}\mathbf{n}^{\circ} \text { vagens } \\
\text { dois grãos }\end{array}$ & $\begin{array}{l}\mathbf{n}^{\circ} \text { vagens } \\
\text { três grãos }\end{array}$ & $\begin{array}{l}\mathbf{n}^{\circ} \text { vagens } \\
\text { quatro grãos }\end{array}$ \\
\hline \multirow{6}{*}{ PROGIBB } & M 8644 IPRO & 11,3 & 60,7 & 26,3 & 0,0 \\
\hline & NS 7901 IPRO & 9,0 & 60,3 & 13,0 & 0,0 \\
\hline & M 7739 IPRO & 5,7 & 49,3 & 47,7 & 0,0 \\
\hline & CZ 48B32 IPRO & 5,7 & 44,3 & 37,7 & 0,0 \\
\hline & HO CRISTALINO & 3,3 & 22,7 & 42,0 & 1,0 \\
\hline & TMG 2185 IPRO & 8,0 & 44,3 & 45,0 & 0,3 \\
\hline \multirow{6}{*}{ STIMULATE } & M 8644 IPRO & 14,3 & 64,0 & 26,3 & 0,0 \\
\hline & NS 7901 IPRO & 8,0 & 95,7 & 18,7 & 0,0 \\
\hline & M 7739 IPRO & 8,7 & 56,3 & 38,3 & 0,3 \\
\hline & CZ 48B32 IPRO & 5,0 & 23,0 & 52,3 & 0,3 \\
\hline & HO CRISTALINO & 3,0 & 34,0 & 50,0 & 0,3 \\
\hline & TMG 2185 IPRO & 3,0 & 44,3 & 45,3 & 0,7 \\
\hline \multirow{6}{*}{ BIOZYME } & M 8644 IPRO & 3,7 & 68,3 & 16,0 & 0,3 \\
\hline & NS 7901 IPRO & 10,3 & 90,7 & 15,7 & 0,3 \\
\hline & M 7739 IPRO & 8,3 & 33,3 & 22,3 & 0,0 \\
\hline & CZ 48B32 IPRO & 8,3 & 35,7 & 31,0 & 0,0 \\
\hline & HO CRISTALINO & 2,7 & 32,7 & 52,0 & 2,0 \\
\hline & TMG 2185 IPRO & 11,0 & 47,0 & 58,7 & 0,3 \\
\hline \multirow{6}{*}{ TESTEMUNHAS } & M 8644 IPRO & 5,7 & 69,3 & 21,3 & 0,0 \\
\hline & NS 7901 IPRO & 6,3 & 86,3 & 18,0 & 0,0 \\
\hline & M 7739 IPRO & 6,3 & 49,7 & 25,7 & 0,3 \\
\hline & CZ 48B32 IPRO & 1,3 & 19,7 & 42,0 & 0,0 \\
\hline & HO CRISTALINO & 6,3 & 29,7 & 52,0 & 0,0 \\
\hline & TMG 2185 IPRO & 9,0 & 45,0 & 42,3 & 0,7 \\
\hline
\end{tabular}

Figura 2 - Desdobramento da interação entre cultivares x bioestimulantes para a variável quantidade total de vagens por planta na cultura da soja em Confresa-MT. IFMT. 2020.

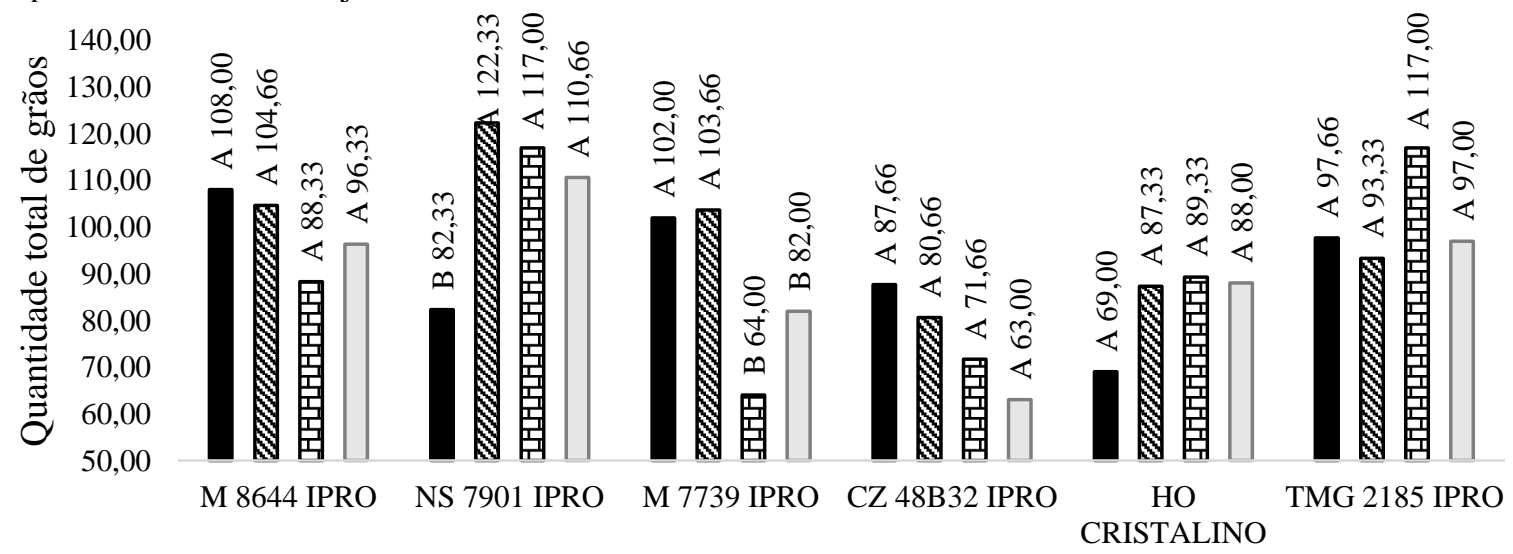

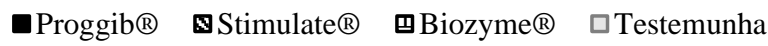

Médias seguidas de mesma letra maiúscula não diferem entre si pelo teste de Scott-Knott $(\mathrm{p} \leq 0,05)$. 
Resultados divergentes foram encontrados por Hermes; Nunes; Nunes (2015), no trabalho eles analisaram a influência do bioestimulante no enraizamento e produtividade da soja e não encontraram resultados significativos para as variáveis comprimento de raiz, número de vagens por planta, número de sementes por planta e massa de 1000 semente. Tais autores reforçaram a ideia de que o resultado não foi o esperado, que fatores externos como temperatura, precipitações e fotoperíodo, podem ter alterado o comportamento da cultura.

Na Figura 3 pode-se observar os valores dos números totais de grãos por planta, a cultivar NS 7901 IPRO quando submetida a aplicação do Stimulate apresentou a maior média de números de vagens, também expressou o maior número de grãos por planta demonstrando a ligação de uma característica com outra, este tratamento assim como no fator de variação anterior, foi significativo para o tratamento onde foi aplicado o Progibb e não foi signifativo em relação ao Biozyme e a testemunha.

Figura 3 - Desdobramento da interação entre cultivares x bioestimulantes para a variável número total de grãos por planta na cultura da soja em Confresa-MT. IFMT. 2020.

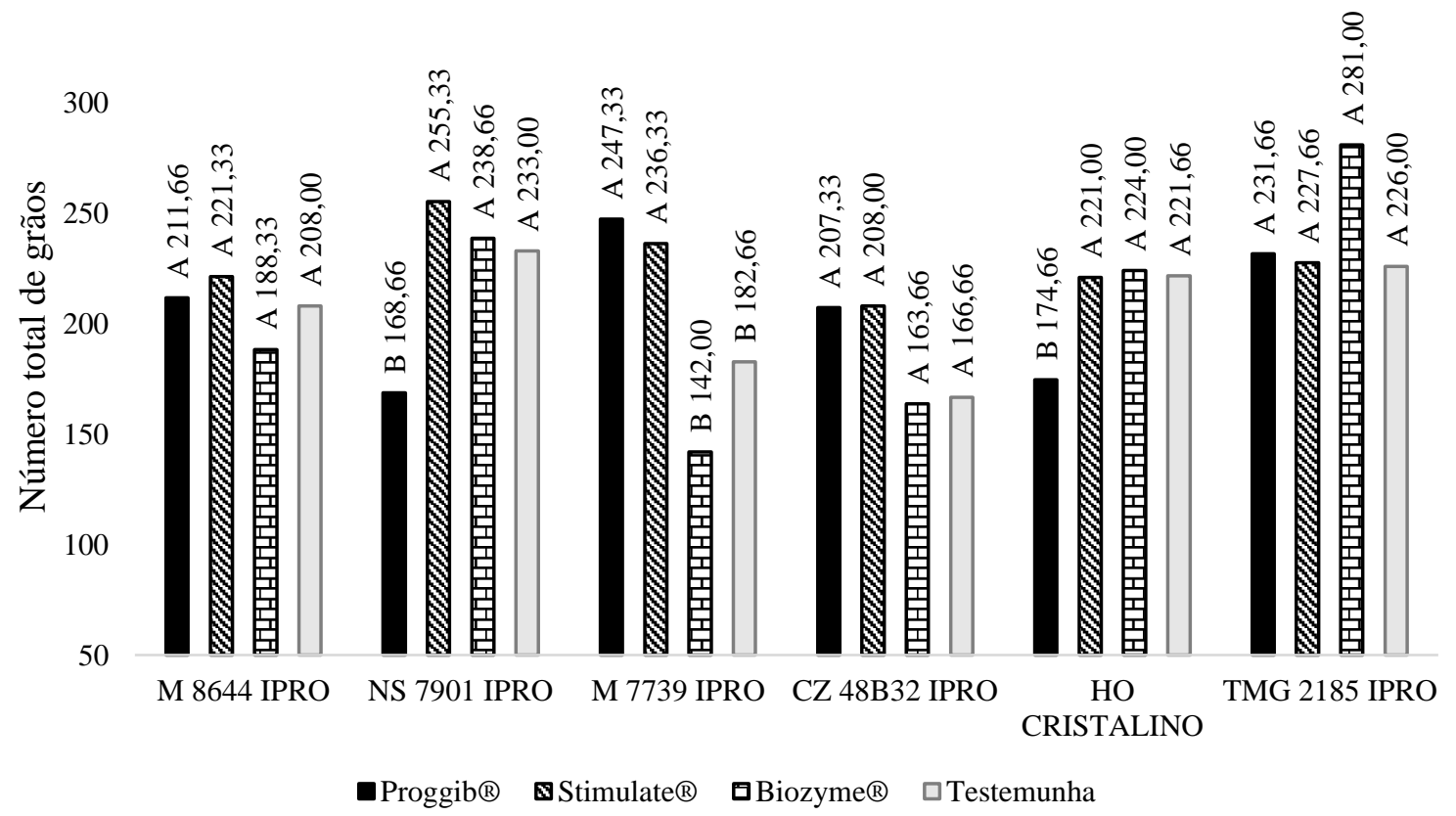

Médias seguidas de mesma letra maiúscula não diferem entre si pelo teste de Scott-Knott $(\mathrm{p} \leq 0,05)$.

Embora não tenha tido a maior média a cultivar M 7739 IPRO foi a que demonstrou maior variância entre os tratamentos para o fator de variação número total de grãos, onde foi aplicado Progibb e Stimulate expressaram maior número de grãos e ambos se diferenciaram do tratamento com Biozyme e da testemunha. Em contrapartida as médias das demais cultivares não demonstraram diferença entre os bioestimulantes utilizados. 
Floss et al. (2007) afirmam que os aminoácidos e hormônios podem favorecer a germinação, proporcionar maiores volumes de raízes, tornar plantas mais vigorosas, ter maior número e enchimento de grãos levando assim a uma maior produção. Marques, Simonetti e Rosa (2014) relataram que em seu trabalho com aspectos produtivos do uso de bioestimulantes na cultura da soja obtiveram resposta positiva em relação ao número de vagens e número de grãos por planta. O trabalho de Batista Filho et al. (2013) evidenciou que o uso de bioestimulantes na soja aumentou o número de grãos e vagens, e consequentemente sua produtividade.

Segundo Carvalho et al. (2013) quando estudaram a produtividade e desenvolvimento da cultura da soja pelo uso de regulador vegetal não encontraram reposta significativa para a variável número de grãos.

Quanto ao peso de mil grãos, foi constatado que os tratamentos com Stimulate ${ }^{\circledR}$ e Proggib® se sobressaíram aos demais, enquanto o Byozime $® \circledR$ só se diferenciou da testemunha na cultivar M 8644 IPRO. Com esses resultados, pode se afirmar que a variável peso de mil grãos sofre influência dos hormônios vegetais, de maneira que a aplicação de pequenas concentrações nas plantas, já resultou em uma expressiva diferença, como demonstra a Figura 4.

Dentre os fatores de variação estudados o que mais variou foi o peso de mil grãos, em todas as cultivares ao menos um bioestimulante foi superior a testemunha, isso se explica pelo fato dos bioestimulantes atuarem diretamente no metabolismo das plantas. Os hormônios vegetais atuam na diferenciação dos cloroplastos, no desenvolvimento do metabolismo autotrófico e na expansão de folhas e cotilédones (TAIZ; ZEIGER, 2004).

No conjunto de cultivares pode-se observar que a M 7739 IPRO teve a maior média entre os tratamentos com 208,71 gramas, não se diferenciando do Progibb (206,34g), com diferença significativa para Biozyme $(172,65 \mathrm{~g})$ e Testemunha que obteve uma redução de 9,22\% em relação a maior média obtida. Resultado semelhante ao da M 7739 IPRO foi encontrado CZ 48B32 IPRO

Nota-se que para o fator de variação massa de mil grãos o manejo com o Stimulate foi superior em três das seis cultivares testadas (M 8644 IPRO, HO CRISTALINO, TMG 2185 IPRO), e obteve diferença significativa em relação ao Biozyme e a testemunha em todas cultivares. 
Figura 4 - Desdobramento da interação entre cultivares x bioestimulantes para a variável peso de mil grãos (g) na cultura da soja em Confresa-MT. IFMT. 2019.

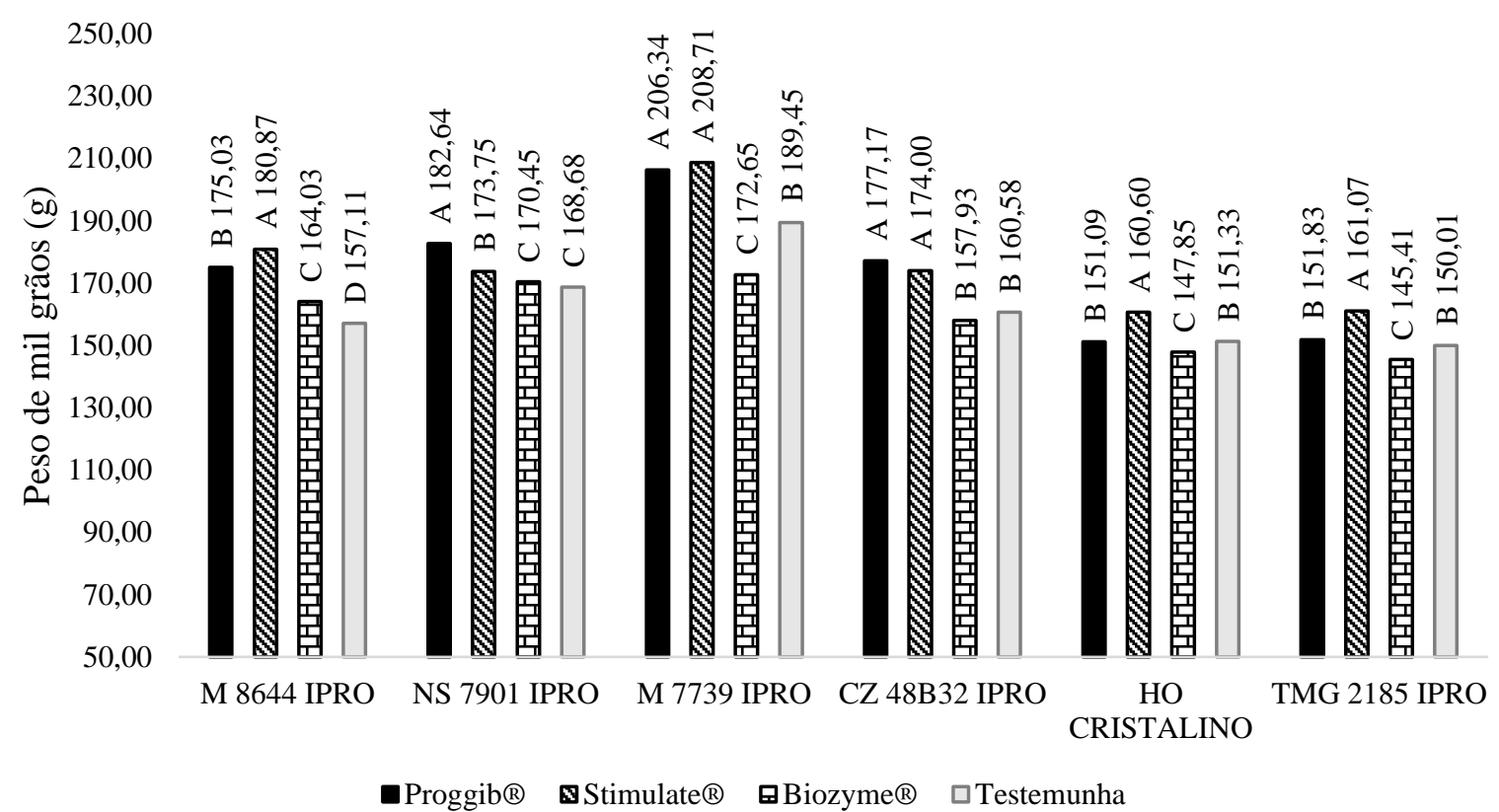

Médias seguidas de mesma letra maiúscula não diferem entre si pelo teste de Scott-Knott $(\mathrm{p} \leq 0,05)$.

Perina et al. (2010) afirmam que a massa de mil grãos pode ser variada, dependendo do tipo de tratamento que foi utilizado e como foi o manejo á campo, sendo estes muito vulneráveis aos produtos administrados e pelo ambiente. Mortele et al (2008) em seu estudo sobre os efeitos da aplicação de biorregulador no desempenho agronômico e produtividade da soja 2006/07, observaram que a aplicação foliar do produto fez com que a massa de mil sementes aumentasse significativamente. Já nos trabalhos de Bourscheidt, (2011) e Scherb et al., (2017), avaliando o uso de bioestimulantes na cultura da soja verificaram que a massa de mil grãos não variou significativamente.

As médias para o fator de variação produtividade estão descritas na Figura 5. Nota-se que as cultivares M 8644 IPRO, M 7739 IPRO, HO CRISTALINO, TMG 2185 IPRO demonstraram variações significativas aos diferentes manejos adotados. A cultivar HO CRISTALINO quando submetida a aplicação do Stimulate teve a maior produção de grãos, com 98,49 sc/ha, não tendo diferença estatística para testemunha com $(97,79 \mathrm{sc} / \mathrm{há})$ e apresentando significância dos tratamentos com Proggib (87,65sc/ha) e Biozyme (87,31sc/ha), uma das características da cultivar HO CRISTALINO é ser altamente responsiva a solos com níveis altos de fertilidade, tal característica explica a razão de não haver diferença significativa entre a testemunha e o tratamento com Stimulate. 
A cultivar M 8644 IPRO quando submetida a aplicação de Progibb e Stimulate apresentou um maior número grão e maior massa de mil grãos e consequentemente maior produtividade, expressando médias estatisticamente iguais para os tratamentos com Proggib 87,82 (sc/ha) e Stimulate (85,09sc/ha) e ambos se diferenciaram dos tratamentos com Biozyme e da testemunha, a diferença entre a maior e menor média para cultivar foi de 16,97 sc/ha.

A cultivar TMG 2185 IPRO no manejo com uso de Stimulate obteve a terceira maior produtividade com 93,63 sc/ha, não se diferenciando para os tratamentos com Proggib $(87,28$ sc/ha) e Biozyme (92,52sc/ha), sendo significativo para Testemunha que obteve uma redução de $17,07 \mathrm{sc} /$ ha para a maior média.

Figura 5 - Desdobramento da interação entre cultivares x bioestimulantes para a variável produtividade na cultura da soja sc/ha em Confresa-MT. IFMT. 2020.

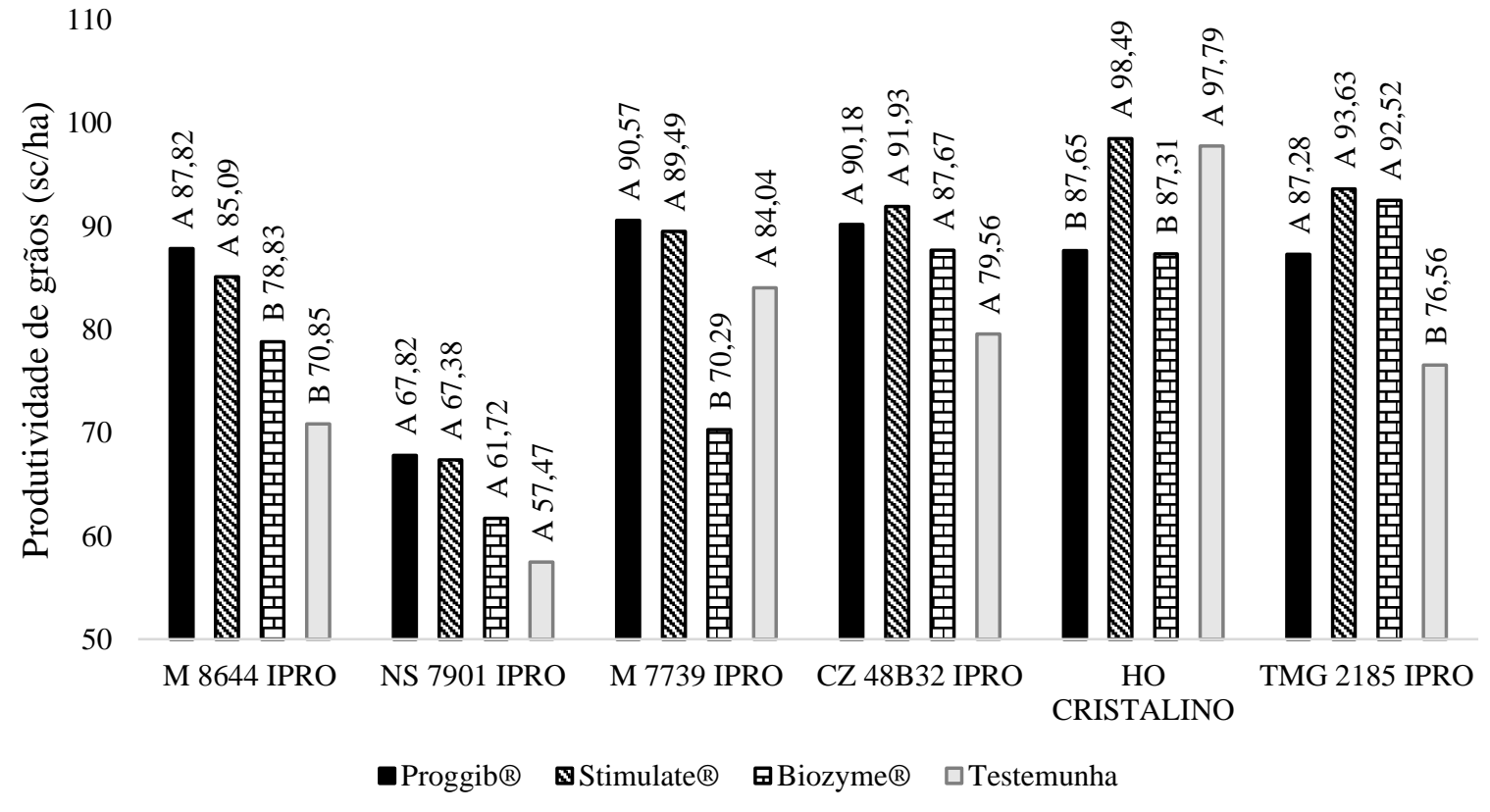

Médias seguidas de mesma letra maiúscula não diferem entre si pelo teste de Scott-Knott $(\mathrm{p} \leq 0,05)$.

A maior diferença entre a menor e maior média entre os tratamentos aconteceu na cultivar M 7739 IPRO que expressou 20,28 sc/ha a mais no tratamento com Proggib em relação ao tratamento com Biozyme. Em relação a diferença entre os tratamentos com bioestimulantes e testemunha só houve diferença significativa nas cultivares M 8644 IPRO e TMG 2185 IPRO. Conceição; Morais (2017) utilizaram o Progibb® 400® na soja e obtiveram respostas positiva, como aumento de produção e viabilidade econômica.

Observa-se entre as cultivares, que no manejo ao uso de Progibb e Stimulate, as cultivares M 8644 IPRO, M 7739 IPRO, CZ 48B32 IPRO, HO CRISTALINO, TMG 2185 IPRO expressaram as maiores médias, enquanto a NS 7901 IPRO demonstrou o menor 
rendimento, com redução de $25 \%$ e $31,5 \%$ respectivamente em relação a maior média. No manejo com Biozyme, a cultivar TMG 2185 IPRO expressou a maior média de 92,52 sc/ha. Em relação a Testemunha a cultivar que teve maior produtividade foi a HO CRISTALINO com 97,79sc/ha.

Klahold et al. (2006) afirmam que a aplicação de bioestimulantes provocou alterações fisiológicas nas plantas, tais alterações podem estar relacionada a atividade fotossintética e principalmente na relação fonte/dreno provocando assim alterações na distribuição de fotoassimilados.

\section{Considerações Finais}

Os bioestimulantes quando utilizados em cultivares de hábito de crescimento determinado e com baixa exigência de fertilidade proporcionam maiores produções na cultura da soja. Em contrapartida as variáveis número de nós por planta e número de ramos reprodutivos não tem variação quanto ao uso de bioestimulantes.

Mais experimentos e pesquisas em condições de campo devem ser realizados, com aplicação via semente, foliar e/ou agregação das duas com diferentes cultivares e bioestimulantes. 


\section{Referências}

ALBRECHT, L. P. et al. Manejo de biorregulador nos componentes de produção e desempenho das plantas de soja. Bioscience Journal, v. 27, p. 865-876, 2011. Disponível em: http://www.seer.ufu.br/index.php/biosciencejournal/article/view/7486. Acesso em: 10 set. 2020.

ALMEIDA, J.C.V. et al. Stimulate ${ }^{\circledR}$ como regulador de crescimento na cultura da soja. In: CONGRESSO BRASILEIRO DE SOJA, 3., Foz do Iguaçu. Anais... Foz do Iguaçu - PR, 2004. Disponível em: https://www.scielo.br/scielo.php?script=sci_arttext\&pid=S180786212008000500015. Acesso em: 12 set. 2020.

ÁVILA, M. R. et al. Bioregulator application, agronomic efficiency, and quality of soybean seeds. Scientia Agricola, v. 65, n. 06, p. 567-691, 2008. Disponível em: https://www.scielo.br/scielo.php?script=sci_arttext\&pid=S0103-90162008000600006. Acesso em: 05 set. 2020. DOI: https://doi.org/10.1590/S0103-90162008000600006

CARVALHO, J.C. et al. Produtividade e desenvolvimento da cultura da soja pelo uso de regulador vegetal. Acta iguazu. Cascavel-PR, 2006. Disponível em: http://erevista.unioeste.br/index.php/actaiguazu/article/view/8166. Acesso em: 05 set. 2020.

BOURSCHEIDT, C. E. Bioestimulante e seus efeitos agronômicos na cultura da soja (glycine Max). 2011. 35 f. Trabalho de Conclusão de Curso - Curso de Agronomia do Departamento de Estudos Agrários da Universidade Regional do Noroeste do Estado do Rio Grande do Sul - UNIJUÍ, Ijuí, 2011.

BATISTA FILHO, C. G. et al. Efeito do Stimulate nas características agronômicas da soja. Acta Iguazu, v. 2, p. 76-86, 2013. Disponível em: https://www.sumarios.org/artigo/efeito-dostimulate\%C2\%AE-nas-caracter\%C3\%ADsticas-agron\%C3\%B4micas-da-soja. Acesso em: 05 set. 2020. DOI: https://doi.org/10.48075/actaiguaz.v2i4.9112

BERTOLIN, D. C. et al. Aumento da produtividade de soja com a aplicação de bioestimulantes. Bragantia, v. 69, n. 2, p. 339-347, 2010. Disponível em: https://www.scielo.br/scielo.php?script=sci_abstract\&pid=S000687052010000200011\&lng=en\&nrm=iso\&tlng=pt\#: :text=A\%20utiliza\%C3\%A7\%C3\%A3o $\% 20 \mathrm{do} \% 20$ bioestimulante $\% 20$ incrementou,foliar $\% 20 \mathrm{n} \% \mathrm{C} 3 \% \mathrm{~A} 3 \mathrm{o} \% 20$ diferiram $\% 20 \mathrm{entre} \% 2$ 0si.\&text $=$ Em\%20rela\%C3\%A7\%C3\%A3o\%20ao\%20aumento\%20da,quando $\% 20$ aplicado\% 20na\%20fase\%20reprodutiva. Acesso em: 12 fev. 2020. DOI: https://doi.org/10.1590/S000687052010000200011 .

CAMPOS, M. F. et al. Análise de crescimento em plantas de soja tratadas com substâncias reguladoras. Revista Biotemas, v. 21, n. 03, p. 53-63, 2008. Disponível em: https://periodicos.ufsc.br/index.php/biotemas/article/view/2175-7925.2008v21n3p53. Acesso em: 12 fev. 2020. DOI: https://doi.org/10.5007/2175-7925.2008v21n3p53.

CONAB. Companhia Nacional de Abastecimento. Acompanhamento da safra brasileira de grãos. Brasília, 2017. Disponível em: http://www.conab.gov.br.Acesso em: 12 fev. 2020. 
CONCEIÇÃO, C. W. M.; MORAIS, O. S. Respostas agronômicas e de viabilidade econômica de dois biorreguladores na cultura da soja no município de Paragominas Pará. Trabalho de Conclusão de Curso (Bacharelado em Engenharia Agronômica). Universidade Federal Rural da Amazônia - UFRA, Paragominas - PA, 2017.

DANTAS, A. C. V. L. et al. Effect of gibberellic acid and the bioestimulant Stimulate $®$ on the initial growth of thamarind. Revista Brasileira de Fruticultura, v. 34, n. 1, p. 008- 014, 2012. Disponível em: https://www.scielo.br/scielo.php?script=sci_arttext\&pid=S010029452012000100004. Acesso em: 12 fev. 2020. DOI: https://doi.org/10.1590/S010029452012000100004.

EMBRAPA. Empresa Brasileira de Pesquisa Agropecuária. Sistema Brasileiro de Classificação de Solos. 3 ed. Rio de Janeiro: Embrapa Solos, 2013.

FERREIRA, D. F. Análises estatísticas por meio do SISVAR para Windows versão 4.0. In: 45 . Reunião Anual da Região Brasileira da Sociedade Internacional de Biometria. 2000. São Carlos. Anais... São Carlos: Universidade Federal de São Carlos, 2000. Disponível em: http://www.ppgest.ufscar.br/documentos/rt/rt27.pdf. Acesso em: 16 fev. 2020.

FETTER, P. R. Hidrolisados de resíduos de raízes e caules de tabaco para estimulação da germinação de sementes de arroz e milho. Dissertação (Pós-Graduação em Tecnologia Ambiental) - Universidade de Santa Cruz do Sul, Santa Cruz do Sul, 2018. Disponível em: http://hdl.handle.net/11624/2249. Acesso em: 01 mar. 2021.

FLOSS, E. L.; FLOSS, L. G. FLOSS, E.L.; FLOSS, L.G. Fertilizantes organo minerais de última geração: funções fisiológicas e uso na agricultura. Revista Plantio Direto, n.100, 2007. Disponível em: http://www.plantiodireto.com.br/?body=cont_int\&id=811.

FUNDAÇÃO MATO GROSSO. Boletim de Pesquisa 2017/2018. Editora Entrelinhas, No $18,2017.336 \mathrm{p}$.

GARCIA, F, O.; CIAMPITTI, I. A.; BAIGORRI H. E. Manual de manejo del cultivo de soja. $1^{a}$ ed. Buenos Aires, AR. International Plant Nutrion Institute. 2009.

GLOVER, J. D.; REGANOLD, J. P.; ANDREWS, P. K. Systematic method for rating soil quality of conventional, organic, and integrated apple orchards in Washington State.

Agriculture, Ecosystems and Environment, v.80, n. 1-2, p.29-45, 2000.

HERMES, E. C. K.; NUNES, J.; NUNES, J. V. D. Influência do bioestimulante no enraizamento e produtividade da soja. Revista cultivando o saber, 2015. Disponível em: <https://www.fag.edu.br/upload/revista/cultivando_o_saber/566ec37d601a3.pdf >. Acesso em: 16 fev. 2020.

KLAHOLD, C. A. et al. Resposta da soja (Glycine max (L.) Merrill) à ação de bioestimulante. Acta Sientiarium Agronomy, v. 28, n. 2, p. 179-185, 2006. Disponível em: http://tede.unioeste.br/handle/tede/1349. Acesso em: 12 fev. 2020.

KOVALSKI, A. R. et al. Avaliação do Desempenho Agronômico de Diferentes Cultivares de Soja (Glycine max (L.) Merrill) Com Uso de Bioestimulantes e Herbicida Hormonal. Revista 
PesquisAgro, v. 3, n. 1, p. 4-24, 2020. Disponível em:

http://periodicos.cfs.ifmt.edu.br/periodicos/index.php/agro/article/view/651/332. Acesso em:

23 fev. 2021.

MAPA. Ministério da Agricultura, Pecuária e Abastecimento. 2014. Disponível em: http://www.agricultura.gov.br/vegetal/culturas/soja. Acesso em: 12 fev. 2020.

MILLÉO, M.V.R.; MONFERDINI, M.A. Avaliação da eficiência agronômica de diferentes dosagens e métodos de aplicação de Stimulate® em soja. In: CONGRESSO BRASILEIRO DE SOJA, 3., Foz do Iguaçu. Anais. Foz do Iguaçu, 2004.

PERINA, E. F.; CARVALHO, C. R. L.; CHIORATO, A. F.; GONÇALVES, J. G. R.; CARBONELL, S. A. M. Avaliação de estabilidade e adaptabilidade de genótipos de feijoeiro (Phaseolus vulgaris L.) baseada na análise multivariada da performance genotípica. Ciência e Agrotecnologia, v. 34, n. 2, p. 398-406, 2010. Disponível em

https://www.researchgate.net/publication/250050718_Avaliacao_da_estabilidade_e_adaptabil idade_de_genotipos_de_feijoeiro_Phaseolus_vulgaris_L_baseada_na_analise_multivariada_d a_performance_genotipica. Acesso em: 12 fev. 2020. DOI: https://10.1590/S141370542010000200018 .

PIMENTEL GOMES, F. Curso de Estatística Experimental. 14.ed. Piracicaba: Degaspari.477p. 2000.

ROCHA, R. S. et al. Desempenho agronômico de variedades e linhagens de soja em condições de baixa latitude em Teresina-PI. Revista Ciência Agronômica, v. 43, n. 1, jan./mar. 2012. Disponível em: http://www.scielo.br/pdf/rca/v43n1/19.pdf. Acesso em: 12 fev. 2020.

SCHERB, C. T. et al. Desempenho e produtividade da cultura da soja mediante a aplicação de biorreguladores. Resumos Expandidos da XXXVI Reunião de Pesquisa de Soja: Comissão de nutrição, fertilidade e biologia dos solos. Londrina, PR, jun. 2017. Disponível em:

https://www.scielo.br/scielo.php?pid=S180786212008000500015\&script=sci_arttext. Acesso em: 10 fev. 2020.

SANTINI, J. M. K.; PERIN, A.; SANTOS, C.G.; FERREIRA, A. C.; SALIB, G.C. Viabilidade técno-econômica do uso de bioestimulantes em sementes de soja. Tecnologia e Ciência Agropecuária, João Pessoa, v. 9, n.1, p. 57-92, Mar. 2015. Disponível em https://revistatca.pb.gov.br/edicoes/volume-09-2015/volume-9-numero-1-marco2015/tca9107.pdf. Acesso em: 12 fev. 2020.

SILVA, T. T. A.; PINHO, E. R. V.; CARDOSO, D. L.; FERREIRA, C. A.; ALVIM, P. O; COSTA, A. A. F. Qualidade fisiológica de sementes de milho na presença de bioestimulantes. Ciência e Agrotecnologia, v. 32, p. 840-846, 2008. Disponível em http://dx.doi.org/10.1590/S1413-70542008000300021. Acesso em: 12 fev. 2020.

SOUZA, E.F. O morango e sua padronização: classificação de produtos. Gleba, v.16, p.6-8, 2003. 
TAIZ, L.; ZIEGER, E. Auxina: o hormônio de crescimento. In: TAIZ, L.; ZIEGER, E. Fisiologia vegetal. 3. ed. Porto Alegre: Artmed, 2004. Cap. 19, p. 449-484.

YEO, I. K.; JOHNSON, R. A. A New Family of Power Transformation to Improve Normality or Symmetry. Biometrika, v.87, n.4, p.954-959, 2000. 